\title{
Police training for the management of dangerous patients
}

\author{
Stephen Logsdail and Kevin Ellis
}

When we call on the police, we can anticipate every officer will have received a basic level of training, which is given at the start of his/her career. This takes place at one of the National Police Training Centres within the UK. Over 10 weeks, new officers are taught self-defence, safety, communication and handcuffing skills. After this they transfer to a local force training centre, where the national training is put into the context of local policies and procedures, using local equipment. The officer works as a probationer for two years before final basic qualification is accepted.

Thereafter the officer can volunteer for specialist training called MAST (Mutual Aid Standard Training). A MAST-trained officer will undergo four discrete training sessions over a 12-month period, and repeat these annually as long as he/ she is active in the work. The areas covered are crowd control, including dispersal and arrest (equipping them to deal with football matches, concerts, protests, demonstrations and riots); prison tactics (to assist with controlling disorderly prisoners); riot shield work; building entry and search; barricade removal; and dealing with "the angry man" (Council of the Association of Chief Police Officers of England, Wales and Northern Ireland, 1994a). Thereafter these officers are called to assist at all forms of public disorder.

The MAST-trained officers make up Police Support Units (PSUs), each of which consists of one inspector, three sergeants and 18 constables. There is one PSU per 280 officers in the UK police force. They are called upon to deal with public disorder throughout the country, although they will work with a firearms support unit if such weapons are thought to be part of the threat.

Psychiatrists may call on the police, and therefore the PSU may be needed for "angry man" and riot shield work, and building entry. So how and what are they taught? The psychiatrist author of this article joined the Thames Valley training to find out.

\section{The training programme}

I was warmly welcomed - all the officers liked a doctor to talk to about the interface areas, for example sudden death in custody, excited delirium, the best ways to approach a person with schizophrenia. There was an open atmosphere, not one promoting suppression and violence to civilians. The emphasis was on doing the job efficiently, professionally and with the minimum of harm to all. First, handcuffing skills were revised - traumatic neuropathies are an important consideration to the police, and this skill is taken seriously by all grades. There was also revision of the use of the side-handled baton. which has been enthusiastically embraced by the police - it provides a good form of defence, and can be used offensively in a graded way, but is unlikely to break bones.

All police defensive and offensive training emphasises communication and negotiation before any action, there is no 'macho' culture. Safety is the priority, for both officer and recipient, and the police practised on each other. They were expected to use reasonable force, but this included the possibility of striking if justified, although they were taught low-, medium- and high-risk areas of the body, and would only touch the latter if under severe threat, for example when at risk of serious harm. Low risk areas include the limbs, pectoral areas and shoulders, medium risk is lower abdomen, and high-risk areas include genitals, middle and upper abdomen. chest, head and neck.

Usually, the aim was to restrain the arm, one officer either side, and a struggling person would be quelled with either the gooseneck hold to the wrist (held flexed and externally rotated); this is found in hospital control and restraint training, or the more assertive arm entanglement hold, a secure arm lock, which like the gooseneck is painless when applied, but can cause pain to effect control.

Pressure points are taught, for example thumb pressure applied to the mandibular angle. the 
knee strike to the outer thigh ('dead leg' from school days), and the medical implications of each considered in detail, so every officer is aware of any potential implications. There is no encouragement on restricting respiration, unless the situation is life threatening, and a subject will be turned to assist breathing if there is the slightest hint of respiratory embarrassment. All defensive and offensive tactics have been agreed at the most senior police levels (Council of the Association of Chief Police Officers of England, Wales and Northern Ireland, 1994b), have received medical scrutiny (and in some cases modifications of techniques has taken place) and been tested in court.

There was a lot of discussion and concern about excited delirium, the condition associated with sudden death in police custody and sometimes in psychiatric units (Farnham \& Kennedy, 1997). This occurs when a struggling individual reaches a stage of exhaustion, yet his aggression (including self-directed) does not abate, and he is unresponsive to his surroundings. A large oxygen debt builds up, and in the setting of drug ingestion or heart disease, sudden cardiac arrest may occur. Although previously recognised (Mann et al, 1986), more research is needed to understand this phenomenon, and it remains a clearly articulated priority for the police to minimise the risk of death in these circumstances. Their current guidelines include sitting a struggling person upright as soon as practicable, and ensuring prompt medical review if confusion persists.

\section{'Taking' a disturbed psychiatric person}

Police preparation for taking and controlling a dangerous psychiatric person is thorough, and by choice the psychiatrist should be involved. Clear guidelines are followed (Thames Valley Police, 1998), and there are six areas for police consideration.

Try to understand the nature of the mental illness, and how it is affecting the person. It is here that the psychiatrist can be of most help and it is good practice to share relevant information, as it helps in the understanding of risk, and thereby reduces possible harm to those involved. The police will wish to bear in mind recent and background factors, including current symptomatology, behaviour and history of dangerousness to property, self or others. Alcohol use will be considered, along with drug ingestion, prescribed and illicit. What are trigger points to avoid mentioning and calming factors to talk about? Key family members or friends may need to be contacted or another important member of the care team. if this will improve understanding and communication, or help deescalate a confrontation.
What is the overall level of risk - is there a risk of firearms being used (for example is the person a member of a gun club)? If so, an armed response vehicle would be deployed. Does he have another sort of weapon (metal bar, machete)? Are there people in the house who might collude or become possible hostages? Does there need to be preservation of evidence if a crime has been committed? Will ambulance and fire services need to be nearby?

Planning and preparation for building entry consideration will be given to door or window entry, floor plan design (including constructing a map, or perhaps visiting a similar neighbouring house) and review of possible escape points which will all need to be covered. If the psychiatrist can confirm the room the patient was in (for example at recent interview), this will be valuable.

Organisation of equipment and the building entry team takes place next. If not all officers are MAST-trained, the police officer in charge will decide if the situation must wait for reinforcements, or if the level of urgency is such that entry must take place before that, with MAST-trained officers at the front, with backup from basic trained officers behind. A dog control warden will be called if a dangerous dog is likely to be encountered.

A briefing of all involved then takes place - this and all previous steps do not have to be done in public gaze, and the police are sensitive not to raise public antipathy by a prolonged and public show of force. Final considerations will include confirmation of police command structure, individual officer tasks, radio communications and transport arrangements.

The legal position will be confirmed. Police may be called to force entry into a building and with the psychiatrist and social worker in attendance. when a Magistrate's warrant is executed in England and Wales under the provisions of Section 135 of the Mental Health Act 1983. which is obtained by the social worker. In Scotland, entry is obtained in similar circumstances under section 83 of the Mental Health (Scotland) Act 1984, and in Ireland under Article 129. Mental Health (Northern Ireland) Order, 1986.

If the police are sent to a situation without a psychiatric team and then find a person at significant immediate risk to self or others they can enter immediately under the Police and Criminal Evidence Act (PACE) section 17, although if they perceive a psychiatric problem, may choose instead to secure the situation and call the duty psychiatric team.

Where the risk of harm is high, officers don protective clothing, including helmets and protective shields. On arrival at the scene, police take over control from the doctor and social 
worker, if already present, when they move into the building, the care staff must be safely out of the way, but be available for consultation.

House entry is effected with a purpose made tool, or sledge hammers if needed. This was rehearsed at training in a mock building, and noise and lighting can be used to heighten tension during training. Once inside, officers (usually two) advance, shields to the front, and either separate or linked, for protection, covering the width of the hallway or passage, for maximum safety. Each room door will be opened in turn shields acting as an 'outer door' for safety, and the room will be searched and secured, before moving on through the building, thus ensuring the police safe area is maximised and predictable. During this process, all exit points, including windows, will be covered externally, and for psychiatric patients, an ambulance will be on hand.

When the patient is found, he will be asked to do as he is told, basically to behave compliantly, and even at this stage the police will make efforts to gain compliance without force, for example by allowing him access to a mobile phone, or talking to a trusted health worker (placed behind the officers). However, if the patient remains uncontrolled and non-compliant, officers advance, two abreast, shields linked to 'squash' him into a corner. Finally, he is pinned by one shield, is told to extend his arms, which are taken as previously described, prior to handcuffing. The bottom of the shield can be used offensively in a downward chopping motion to assist gaining control, but not initially as it may graze the legs.

After securing the patient, consideration will be given to whether a charge is necessary, transport to the police station is most appro- priate, or directly to the hospital. Again, it will be important for the doctor to be available for consultation. The police have to complete their own incident sheet, detailing everything done, including how physical restraint was applied, in enough detail to stand up to cross questioning in a courtroom many years later if needed. The doctor should consider talking with the officer in charge after the event is over, to get feedback on how the process went from the police perspective. A brief note of thanks to the area senior police officer is always appreciated and is good public relations.

\section{References}

COUNCIL OF THE ASSOCIATION OF CHIEF POLICE OfFICERS OF England, Wales AND Northern IREland (1994a) Public Order Manual. London: ACPO.

- (1994b) Unarmed Defensive Tactics. A Manual Outlining Policy - Procedure - Techniques. London: ACPO.

FARnham, F. R. \& KenNedy, H. G. (1997) Acute excited states and sudden death. British Medical Journal, $\mathbf{3 1 5}$. 1107-1108.

ManN, S. C.. CAROFf, S. N., Bleier, H. R., et al (1986) Lethal catatonia. American Journal of Psychiatry. 143. 1374-1381.

Thames VALLEY POLICE (1998) Method of Entry: A guide to Planning and Organising a Forced Bullding Entry. London: Thames Valley Police.

*Stephen Logsdail, Consultant Psychiatrist, Tindal Centre, Bierton Road, Aylesbury, Bucks HP2O 1HU; and Kevin Ellis, International Police Training Officer, Public Order Department, Thames Valley Police Headquarters, Kidlington, Oxford

*Correspondence 